\title{
Melacak Jejak Kepengarangan Sastrawan Bali Modern Pra-Kemerdekaan
}

\author{
I Gede Gita Purnama Arsa Putra, I Putu Eka Guna Yasa \\ Fakultas Ilmu Budaya, Universitas Udayana \\ [gita_purnama@unud.ac.id],[guna_sasda@yahoo.co.id] \\ Denpasar, Bali, Indonesia
}

\begin{abstract}
Modern Balinese literature is one of the fields of classification in the world of Balinese literature. Balinese literary works that were born in the modern era or after the inclusion of foreign cultural influences in Balinese literary works are called modern Balinese literature. At the beginning of its emergence in the pre-independence era, modern Balinese literature was conceived by teacher teachers who served in formal schools established by the Dutch colonial. The early works of these teachers became a milestone in the birth of modern Balinese literature. Narrative texts written by I Made Pasek and Mas Niti Sastro became the initial embryos of Balinese short stories. In the form of some narrative texts they have presented a very modern form, no longer similar to the form of narrative doengeng or folklore. Then in content, the value content offered by the author is a very modern value content, not merely the values of tradition.
\end{abstract}

Keywords: modern Balinese literature, short stories, pre-independence

\begin{abstract}
Abstrak
Sastra Bali modern merupakan salah satu bidang klasifikasi dalam dunia sastra Bali. Karya sastra Bali yang lahir pada jaman modern atau setelah masuknya pengaruh kebudayaan asing dalam karya sastra Bali disebut dengan kesusastraan Bali modern. Pada awal kemunculannya di era pra-kemerdekaan, sastra Bali modern digagas oleh mantri guru yang bertugas di sekolah formal yang didirikan kolonial Belanda. Karya-karya awal para guru ini menjadi tonggak lahirnya sastra Bali modern. Teks-teks naratif yang ditulis oleh I Made Pasek dan Mas Niti Sastro menjadi embrio awal cerpen berbahasa Bali. Secara bentuk beberapa teks naratif mereka sudah menyajikan bentuk yang sangat modern, tidak lagi serupa bentuk narasi doengeng atau cerita rakyat. Kemudian secara isi, kandungan nilai yang ditawarkan oleh pengarang merupakan kandungan nilai yang sangat modern, tidak semata-mata nilai-nilai tradisi.
\end{abstract}

Kata kunci: sastra bali modern, cerpen, pra-kemerdekaan

\section{PENDAHULUAN}

Sastra Bali modern (anyar) merupakan salah satu bidang klasifikasi dalam dunia sastra Bali. Karya sastra Bali yang lahir pada jaman modern atau setelah masuknya pengaruh kebudayaan asing dalam karya sastra Bali disebut dengan kesusastraan Bali modern (anyar). Kesusastraan Bali modern (Anyar) terdapat dalam bentuk novel, cerpen, drama dan puisi (Bagus dan Ginarsa, 1978). Hal menarik dalam sastra
Bali modern (anyar) adalah bahwa sastra Bali modern merupakan "sastra peranakan". Tubuhnya (strukturnya) merupakan perwujudan sastra modern, sedangkan idenya khas Bali.

Perkembangan sastra Bali modern sejak awal kemunculannya tahun 1910an, tidak bisa dilepaskan dari peran besar para sastrawan yang berkiprah di bidang sastra Bali modern. Para sastrawan yang mencetuskan kelahiran sastra Bali modern di masa pra-kemerdekaan adalah

\begin{tabular}{lll}
\hline Info Article & & \\
\hline Received & $:$ & $3^{\text {rd }}$ October 2020 \\
Accepted & $:$ & $10^{\text {th }}$ November 2020 \\
Published & $:$ & $30^{\text {th }}$ November 2020
\end{tabular}


pionir-pionir yang meletakkan pondasi, selanjutnya pasca kemerdekaan dilanjutkan dengan generasi sastrawan di bawahnya. Peran besar para sastrawan dalam usaha-usaha dan berkarya untuk sastra Bali modern pra-kemerdekaan dan pascakemerdekaan perlu mendapat catatan khusus.

Sastrawan pra-kemerdekaan adalah sastrawan yang sebagian besar berprofesi sebagai guru di sekolah formal bentukan kolonial Belanda. I Made Pasek adalah salah satu sastrawan yang berperan besar dalam kelahiran sastra Bali modern. Sebagai mantri guru di sekolah formal milik kolonial, ia berperan besar dalam membuat buku ajar untuk siswa-siswa sekolah. Sejauh ini belum banyak diungkap latar belakang I Made Pasek sebagai salah satu sastrawan yang berperan besar meletakkan pondasi sastra Bali modern. Karya-karya I Made Pasek juga tidak banyak dibahas sebagai sebuah karya sastra yang menjadi embrio berkembangnya sastra Bali modern.

Selain I Made Pasek, terdapat nama Mas Niti Sastro yang juga merupakan salah seorang guru di sekolah formal bentukan kolonial. Mas Niti Sastro adalah seorang guru yang bukan berasal dari Bali, namun banyak menulis buku ajar dengan bahasa Bali. Ini merupakan salah satu hal menarik yang sebelumnya tidak secara mendalam diungkapkan. Pengungkapan sepintas tentang dua sastrawan Bali modern ini terdapat dalam buku karya Nyoman Darma Putra “Tonggak Baru Sastra Bali Modern".

I Wajan Gobiah adalah sastrawan selanjutnya yang turut berkarya dalam dunia sastra Bali modern prakemerdekaan. Selama ini data diri I Wajan Gobiah masih sangat gelap, tidak banyak yang mampu menelusuri latar belakang I Wajan Gobiah. Sumbangsih I Wajan Gobiah dalam dunia sastra Bali modern adalah sebuah roman pertama dalam sastra Bali modern berjudul
"Nemoe Karma". Selain pengarangnya yang tidak banyak diungkap selama ini, karya sastra fenomenal ini pula tidak banyak yang mengulas secara mendalam.

Gede Srawana merupakan salah satu sastrawan sastra Bali modern prakemerdekaan. Karyanya berupa novel merupakan novel pertama dalam sejarah sastra Bali modern. Sebab selanjutnya setelah novel pertama dengan judul "Mlantjaran ka Sasak", tidak muncul lagi dalam catatan sejarah sastra Bali modern pra-kemerdekaan.

Menjadi satu hal yang sangat penting untuk mengungkapkan sejauh mana keberadaan para pengarang sastra Bali pra-kemerdekaan serta karya-karya yang telah dihasilkan. Demikian juga dengan kekuatan karya-karya yang mereka hasilkan, khususnya bagaimana karya mereka dapat digolongkan sebagai karya pionir dalam dunia sastra modern di Bali.

\section{METODE}

Penelitian ini merupakan penelitian kualitatif dengan data utama penelitian yang terdiri atas : (a) informasi dari sastrawan maupun keluarga sastrawan Bali modern, (b) karya tulis berupa artikel, berita koran, maupun tulisan ilmiah seputar sastra Bali modern dan (c) karya-karya sastra Bali modern yang terbit pada masa pra-kemerdekaan.

Data untuk penelitian ini berwujud sejumlah data tulis dan data informasi dari informan yang telah direkam. Hasil wawancara terhadap informan baik dari kalangan sastrawan maupun keluarga sastrawan diharapkan memberikan informasi yang lebih komprehensip dan valid. Pemilihan data tulis yang merupakan artikel-artikel maupun tulisan dan catatan pribadi milik pengarang. Pemilihan data tulis ini diharapkan mampu memberikan gambaran tentang bagaimana proses kepengarangan maupun proses kreatif pengarang- 
pengarang pra-kemerdekaan yang telah meninggal.

Hasil penelitian ini adalah analisis data baik berupa hasil pengumpulan informasi dari pihak sastrawan dan keluarganya, serta hasil analisis karya para sastrawan Bali modern prakemerdekaan. Penyajian hasil penelitian dalam bentuk informal berupa uraian secara deskriptif dengan menggunakan uraian kata-kata yang lengkap, rinci dan terurai cermat.

\section{HASIL DAN PEMBAHASAN}

\section{Pengarang Pra-Kemerdekaan Sastra Bali Modern dan Karyanya.}

Pengarang sastra Bali modern prakemerdekaan yang akan diulas dalam penelitian ini adalah I Made Pasek dan Mas Niti Sastro. I Made Pasek adalah pengarang yang paling aktif menulis buku, meski tidak semua hasil karya yang dihasilkan olehnya adalah karya sastra Bali modern. Berdasarkan cerita keluarga tertua serta didukung beberapa arsip yang dimiliki dalam dokumen keluarga akhirnya dapat diupayakan pembuatan silsilah garis keluarga I Made Pasek hingga generasi terakhir saat ini. I Made Pasek sendiri adalah anak kedua dari tujuh bersaudara yang tinggal di wilayah Banjar Paket Agung Singaraja. Ayah dan Ibu I Made Pasek adalah orang yang cukup dipandang di lingkungan Banjar Paket Agung karena mereka tergolong keluarga yang memiliki keterampilan khusus yaitu memahami pengokbatan tradisional (Balian) serta memiliki kemampuan bersastra yang sangat baik. Hal ini ditunjukkan dengan jumlah naskah lontar koleksi keluarga I Made Pasek cukup banyak, sekitar 157 cakep (bundel) naskah lontar dengan berbagai varian dan genre. Sebagian besar adalah naskah-naskah yang berkaitan dengan ilmu pengobatan tradisional serta padewasan (penentuan hari baik).
I Made Pasek diperkirakan lahir pada tangggal 23 April 1889 (Anggara Pahing Bala $)^{1}$. Kemudian I Made Pasek memiliki seorang istri yang bernama $\mathrm{Ni}$ Nyoman Taman. I Made Pasek menikah dengan Ni Nyoman Taman dan memiliki beberapa anak namun sebagian besar meninggal saat berumur sangat muda. I Made Pasek diiperkirakan meninggal sangat muda, sekitar umur 30-an tahun. Selama masa hidupnya I Made Pasek menghasilkan kurang lebih 12 judul buku yang diterbitkan dan sebarluaskan oleh lembaga kolonial. Berikut adalah 12 buku karya I Made Pasek:

\footnotetext{
${ }^{1}$ informasi didapatkan berdasarkan hasil wawancara dan pelacakan data pribadi milik keluarga besar I Made Pasek yang bertempat tinggal di Banjar Paket Agung, Singaraja, Bali.
} 


\begin{tabular}{|c|c|c|c|}
\hline $\mathrm{NO}$ & Judul Karya & Penerbit & $\begin{array}{l}\text { Tahun } \\
\text { Terbit }\end{array}$ \\
\hline 1 & $\begin{array}{l}\text { Tjatoer Perenidanâ, Peratamaning } \\
\text { tjakepan pâpeladjahan sang mâmanah } \\
\text { maoeroek mâmaos aksarâ Belanda }\end{array}$ & $\begin{array}{l}\text { Semarang-Drukkereij } \\
\text { en Boekhandel } \\
\text { H.A. Benjamins }\end{array}$ & 1913 \\
\hline 2 & 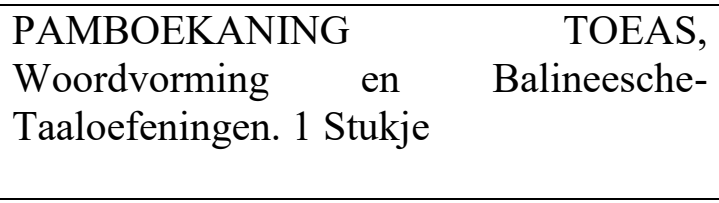 & Landsdrukkerij & $\begin{array}{l}1915 / 16 \\
1922 \\
\text { (cetak } \\
\text { ulang) }\end{array}$ \\
\hline 3 & $\begin{array}{l}\text { PAMBOEKANING } \begin{array}{r}\text { TOEAS, } \\
\text { Woordvorming en } \\
\text { Taaloefeningen. 2 Stukje }\end{array} \\
\end{array}$ & Landsdrukkerij & $1915 / 16$ \\
\hline 3 & $\begin{array}{l}\text { TJAKEPAN EKA-LAWIA, Inggih } \\
\text { poenika TjaTjakan Mekekoedang- } \\
\text { koedang Raos Bali Kesoerat Antoek } \\
\text { Sastera Belanda }\end{array}$ & Landsdrukkerij & 1916 \\
\hline 4 & $\begin{array}{l}\text { ANEKA-ROEPA KITAB BATJAAN } \\
\text { oentoek Disekolah-sekolahan Bali } \\
\text { Pangkat III }\end{array}$ & Landsdrukkerij & 1916 \\
\hline 5 & $\begin{array}{l}\text { BOEKOE-DICTEE BAHASA BALI } \\
\text { HOEROEF BALI, oentek Goeroe- } \\
\text { Goeroe Disekolah Boemi-Poetra } \\
\text { Dikeresidenan Bali dan Lombok }\end{array}$ & Landsdrukkerij & 1916 \\
\hline 6 & Satua Ni Dyah Tantri & Landsdrukkerij & 1916 \\
\hline 7 & $\begin{array}{l}\text { TJAKEPAN PEOMONGAN BALI, } \\
\text { Kangge ring Pangkat I }\end{array}$ & Landsdrukkerij & 1918 \\
\hline 8 & PINAKIT PANINGALAN & $\begin{array}{l}\text { Gudenung Pengecapan } \\
\text { Gubermen ring Betawi } \\
\text { (Landsdrukkerij) }\end{array}$ & 1918 \\
\hline 9 & $\begin{array}{l}\text { ANEKA-WARNA, Tjakepan Kaping } \\
\text { Kalih, Pepaosan Bali Kesoerat } \\
\text { Aksara Belanda }\end{array}$ & Landsdrukkerij & $\begin{array}{l}1918 \\
1919 \\
\text { (cetak } \\
\text { ulang) }\end{array}$ \\
\hline 10 & $\begin{array}{l}\text { KITAB PERTJAKAPAN } \\
\text { Terpakai Pada Pangkat I }\end{array}$ & Landsdrukkerij & 1919 \\
\hline 11 & $\begin{array}{ll}\text { TJAKEPAN } & \text { BALI } \\
\text { BELANDA } & \end{array}$ & $\begin{array}{l}\text { Drukkerijen Ruygrok \& } \\
\text { co. }\end{array}$ & 1921 \\
\hline 12 & ANEKA-WARNA, & $\begin{array}{l}\text { Drukkerijen Ruygrok \& } \\
\text { co. }\end{array}$ & 1921 \\
\hline
\end{tabular}

Semua buku yang ditulis oleh I Made Pasek menjadi buku rujukan pada sekolah-sekolah formal buatan Belanda di Bali. diantara ke-12 buku tersebut hanya buku "ANEKA-WARNA" dan "ANEKA-WARNA, Tjakepan Kaping Kalih, Pepaosan Bali Kesoerat Antoek
Aksara Belanda" yang mengandung cerpen, selebihnya buku-buku karya I Made Pasek adalah buku pelajaran yang mengandung teks naratif bersifat didaktif.

\footnotetext{
${ }^{2}$ ANEKA WARNA, Buku Kedua, Bacaan Bali Ditulis Dengan Aksara Belanda.
} 
Buku "ANEKA-WARNA" berisi 30 teks dengan bahasa Bali dengan menggunakan aksara latin, namun rupanya aksara latin disebut dengan istilah aksara Belanda. Nampaknya pada saat itu, segala yang "asing" disebut dengan Belanda (Putra, 2010). Terdapat 29 teks deskriptif dalam buku ini, dan merupakan teks berbentuk wacana yang memiliki kandungan dedaktif, serta lebih pada bentuk sebuah teks yang merupakan penjelasan tentang sebuah objek. Misalnya adalah pada teks berjudul "Kambing", teks ini menjelaskan bagaimana bentuk fisik hewan kambing, kebiasaan dalam pemeliharaanya, hingga produk-produk olahan yang umumnya dari ternak kambing. Contoh teks lainnya berjudul "Poejan Asem"" , merupakan sebuah wacana yang menjelaskan tentang pohon asam (tamarindus indica) secara morfologi tumbuhan serta pemanfaatannya pada masyarakat.

Pada buku ini, terdapat satu teks yang mengandung unsur naratif yang berjudul "Keneh djoedjoer dadi moedjoer". Teks ini memiliki alur bercerita yang runut. Memiliki tokohtokoh yang menggerakkan alur cerita. Teks terdiri dari narasi dan dialog antar tokoh yang berperan dalam cerita. Teks ini juga memiliki konflik yang melibatkan para tokohnya. Alur konflik pun sangat lengkap mulai dari tahapan kemunculan konflik, konflik memuncak, dan penyelesaian konflik. Karakteristik teks ini sangat mendekati karakteristik karya sastra, khususnya cerpen.

Buku "ANEKA-WARNA, Tjakepan Kaping Kalih, Pepaosan Bali Kesoerat Antoek Aksara Belanda", berisi 33 teks. Dari semua teks yang ada dalam buku ini, jenisnya lebih beragam dari buku pertama. Jenis teks yang muncul dalam buku ini adalah teks deskriptif, teks naratif, dan teks berbentuk kutipan kalimat-kalimat berupa petuah.

Teks deskriptif dalam buku ini terdiri dari 20 buah. Kemudian teks naratif terdiri dari 11 buah, dan 2 buah teks yang berbentuk kumpulan kalimat petuah. Teks deskriptif yang berjumlah 20 buah tidak jauh berdeda dengan buku pertama yaitu mendeskripsikan sebuah objek dengan cukup mendetail, objeknya berupa sebuah benda maupun sebuah pekerjaan. Kemudian 11 teks naratif yang ada dalam buku ini beberapa diantaranya adalah bentuk cerita rakyat (satua) atau legenda yang ditulis ulang ke dalam bahasa Bali. Sebagiannya lagi adalah teks naratif yang merupakan kreasi baru dengan kandungan unsur intrinsik dan memenuhi kaedah sebuah karya sastra cerpen.

Selain I Made Pasek, Mas Niti Sastro juga menulis buku untuk kebutuhan sekolah formal. Buku-buku yang ditulis oleh Mas Niti Sastro tidak terlampau banyak, hanya terdapat 2 buah buku yang berhasil ditemukan sejauh ini. Kedua buku tersebut adalah buku-buku berbahasa dan beraksara Bali yang juga diterbitkan oleh penerbitan pemerintah kolonial. Dua buku karya Mas Niti Sastro adalah "Warna Sari, Tjakepan Bali Sastera Belanda" (penerbit: Landsdrukkerij, tahun 1925), dan Balineesche Schrijetaal (penerbit: Landsdrukkerij, tahun 1918). Buku "Warna Sari, Tjakepan Bali Sastera Belanda" yang

mengandung karya-karya cerpen. Buku kedua adalah buku tentang sistem penulisan pada aksara Bali.

Buku "Warna Sari, Tjakepan Bali Sastera Belanda" berisi 30 teks. Teks yang terdapat dalam buku ini terdapat beberpaa jenis, diantaranya teks deskriptif, teks naratif, teks peribahasa, dan teks dengan kandungan petuah (tutur).

\footnotetext{
${ }^{3}$ Pohon Asam
} 


\section{Struktur Karya-Karya I Made Pasek dan Mas Niti Sastro}

Karya-karya I Made Pasek dalam "ANEKA-WARNA I" dan "ANEKAWARNA II, Tjakepan Kaping Kalih, Pepaosan Bali Kesoerat Antoek Aksara Belanda" terdapat 5 buah yang dapat digolongkan sebagai sebuah cerpen. Karya-karya tersebut tersebut diantaranya adalah "Keneh djoedjoer dadi moedjoer"( ANEKA-WARNA I, 1921:24), "I Kelioed tekēn I Teragiă" (ANEKAWARNA II, 1919 :6), "Ajam Mepaloe" (ANEKA-WARNA II, 1919: 42), "Pemadat" (ANEKA-WARNA II, 1919: 50), "Djelèn anakè demen nginem inoeminoeman anē mekadă poenjah" (ANEKA-WARNA II, 1919: 56).

Sementara karya-karya Mas Niti Sastro dalam buku "Warna Sari, Tjakepan Bali Sastera Belanda” terdapat 2 buah teks naratif yang dapat digolongkan sebagai cerpen. Karya-karya tersebut diantaranya adalah "Anak Ririh"( Warna Sari, Tjakepan Bali Sastera Beland,.... ) dan "Loba" (Warna Sari, Tjakepan Bali Sastera Beland,....). Ketujuh karya I Made Pasek dan Mas Niti Sastro yang masuk dalam kategori cerpen adalah karya-karya teks naratif yang memenuhi kaidah cerpen secara umum.

Secara umum cerpen adalah sebuah karya sastra berbentuk prosa yang selesai dibaca dalam 'sekali duduk'. Cerita pendek hanya memiliki satu arti, satu krisis, dan menghadirkan satu efek pada pembacanya. pengarang menghadirkan hanya satu penajaman pesan (Sumardjo, 2001).

Semenara Nurgiantoro menyebutkan bahwa cerpen terdiri atas unsur intrinsik dan ekstrinsik. Secara ekstrinsik cerpen mengandung unsur peristiwa, plot, tema, tokoh, latar dan sudut pandang. Karena ruang yang tidak panjang, maka cerpen tidak menghadirkan hal-hal yang tak penting (2010).
Cerpen-cerpen karya I Made Pasek dan Mas Niti Sastro rata-rata sepanjang 1-3 halaman buku dengan ukuran A5, dengan jumlah halaman ini maka karyakarya mereka dapat dipastikan habis dibaca dalam sekali duduk. Masingmasing cerpen menghadirkan satu titik masalah yang menjadi pusat penceritaan dengan menghadirkan konflik tunggal pada tokoh utamanya. Tokoh yang hadir dalam ketujuh cerpen ini tidak banyak, hadir dua sampai tiga tokoh yang mengambil peran sebagai tokoh utama, tokoh sekunder maupun tokoh pelengkap.

Pada cerpen "Keneh djoedjoer dadi moedjoer ${ }^{4}$, pengarang menghadirkan satu titik penceritaan pada seorang tokoh utama yang menemukan sebuah peti berisi harta berharga disebuah tanah yang ia garap. Temuan peti ini menjadi pusat penceritaan antar tokoh utama,

\section{Berkarakter Didaktif}

Cerpen-cerpen karya I Made Pasek dan Mas Niti Sastro adalah cerpen-cerpen yang hadir sebagai bagian dari buku pelajaran sekolah. Sebagai salah satu media pembelajaran yang diberikan kepada siswa, cerpen-cerpen ini menghadirkan isi yang mampu memberikan edukasi pada siswa. Melalui tokoh dengan berbagai karakteristik, pengarang menyampaikan pesan-pesan edukatif pada pembaca. Sifat didaktif pada cerpen-cerpen ini menjadi salah satu kekuatan dasarnya

\section{REFERENSI}

Bungin, Burhan. (2003). Analisis Data Penelitian Kualitatif:

Pemahaman Filosofis dan Metodologis ke Arah Penguasaan Model Aplikasi. Jakarta: Raja Grafindo Persada

\footnotetext{
${ }^{4}$ Niat Jujur Jadi Mujur
} 
Dharna, I Gede dan Sanggra I Made. (1973). "Memajukan Sastra Bali Modern dalam Hubungannya dengan Ejaan yang Disempurnakan", makalah dalam Loka Karya Penyesuaian Ejaan Bahasa Bali ke Huruf Latin dengan EYD.

Edy, Nyoman Tusthi. (1991). Mengenal Sastra Bali Modern. Jakarta : Balai Pustaka.

Gobiah, I Wayan. (1931). Nemoe Karma. Jakarta: Balai Bahasa.

Lembaga Bahasa Nasional Tjabang I Singaradja. (1971). Pakeling Petangdasa Warsa Wedalan Sastra Bali Anjar. Singaraja: Lembaga Bahasa Nasional Tjabang I Singaradja.

Luxemburg, Jan Van, dkk. (1982). Pengantar Ilmu Sastra (Terj. Dick Hartoko). Jakarta: PT Gramedia.

Putra, I Nyoman Darma. (2008). Bali dalam Kuasa Politik. Denpasar: Arti Foundation.

Putra, I Nyoman Darma. (2010). Tonggak Baru Sastra Bali Modern. Denpasar: Pustaka Larasan.

Semi, Atar. (1988). Anatomi Sastra. Padang: Angkasa Raya.

Subroto, Edi. (1992). Pengantar Metode Penelitian Linguistik Struktural. Surakarta:Sebelas Maret University Press.

Sudaryanto, (1993). Metode dan Aneka Teknik Analisis Bahasa. Yogyakarta:Duta Wacana
Tarigan, Henry Guntur. (1984). Prinsipprinsip Dasar Sastra. Bandung: Angkasa.

Wellek, Rene \& Austin Warren. (1990). Teori Kesusastraan (Terj. Melani Budianta). Jakarta: PT Gramedia. 